\title{
Analytical Review of Tinnitus Questionnaires: Characteristics and Understanding
}

\author{
Jangwon Lee ${ }^{1}$, Kyungju Lee ${ }^{1}$, Hongyeop Oh', Seungyeop Jeong ${ }^{1}$, In-Ki Jin² \\ 'Department of Speech Pathology and Audiology, Graduate School, Hallym University, Chuncheon, Korea \\ ${ }^{2}$ Division of Speech Pathology and Audiology, Research Institute of Audiology and Speech Pathology, College of Natural Sciences, \\ Hallym University, Chuncheon, Korea
}

\author{
이명 설문지의 특징과 이해를 위한 분석 \\ 이장원 ${ }^{1} \cdot$ 이경주 ${ }^{1} \cdot$ 오홍엽 ${ }^{1} \cdot$ 정승엽 ${ }^{1} \cdot$ 진인기 ${ }^{2}$
}

한림대학교 일반대학원 언어병리청각학과', 한림대학교 자연과학대학 언어청각학부· 청각언어연구소 ${ }^{2}$

\begin{abstract}
For decades, tinnitus questionnaires have used as an effective tool to evaluate the degree of tinnitus relief or a patient's subjective perception of tinnitus. The purpose of this study was to review four tinnitus questionnaires that have primarily been used in clinics. The Tinnitus Handicap Questionnaire (THQ), Tinnitus Handicap Index (THI), Tinnitus Functional Index (TFI), and Tinnitus Primary Functional Questionnaire (TPFQ) were reviewed for development background, purpose of development, developmental process, questionnaire characteristics, reliability test results, and pros and cons of each questionnaire. Each tinnitus questionnaire has their own characteristics in terms of evaluations and interpretations. Especially, the THQ is focused on social, emotional, and physical impacts and the THI is focused on catastrophic loss of life, functional, and emotional factors. The TFI is mainly focused on quality of life, cognitive, and emotional factors. The TPFQ is focused on hearing, sleep, concentration, and emotional factors. The current study provides detailed information about four questionnaires. If each questionnaire is correctly identified and applied, effective measures of tinnitus and the degree of tinnitus relief through rehabilitation can be efficiently measured.
\end{abstract}

Key Words: Tinnitus Handicap Questionnaire, Tinnitus Handicap Index, Tinnitus Functional Index, Tinnitus Primary Functional Questionnaire.

Received: February 26, 2018 / Revised: March 22, 2018 / Accepted: March 26, 2018

Correspondence: In-Ki Jin, Division of Speech Pathology and Audiology, Research Institute of Audiology and Speech Pathology, College of Natural Sciences, Hallym University, 1 Hallimdaehak-gil, Chuncheon 24252, Korea

Tel: +82-33-248-2221 / Fax: +82-33-256-3420 / E-mail: inkijin@hallym.ac.kr

\section{INTRODUCTION}

이명은 외부에 소리 자극이 없음에도 불구하고 귀 또는 머리 에서 소리가 감지되는 증상을 말한다(Møller, 2011; Nondahl et al., 2002). 또한 이명은 불면증, 우울증, 불안, 분노, 집중력 감 소 등과 같은 다양한 이차적인 문제를 동반할 수 있다(Scott et al., 1990; Tyler \& Baker, 1983). 심한 이명의 경우에는 개인의 삶 전체에 걸쳐 부정적인 영향을 줄 수 있으며 때론 자살에 이 르는 경우도 보고되었다(Møller, 2011).

이명은 기전이 명확한 객관적 이명과 기전을 파악하기 어려 운 주관적 이명으로 분류할 수 있으며, 주관적 이명의 경우 이 명을 느끼고 있는 본인을 제외한 사람은 이명을 자각할 수 없
는 특징이 있다(Kreuzer et al., 2013). 주관적 이명은 소리의 주 파수 대역이 매우 넓고 다양한 특징을 갖고 있으며, 이명을 자 각하는 시간이 불규칙적이다. 또한, 주관적 이명은 본인만이 자 각할 수 있으므로 이명의 정도 및 재활에 따른 이명의 경감 (relief) 정도를 객관적으로 측정하기에는 한계가 있다(Møller, 2011). 이런 이유로 현재 임상에서 이명의 정도 및 재활의 효과 를 확인하는 방법으로 이명 설문지가 사용된다.

이명 설문지는 이명으로 인한 청각, 인지, 심리 등 삶의 전반 적인 부분에 미치는 영향을 실제 이명을 자각하는 사람의 관점 에서 알 수 있는 장점이 있으며, 낮은 비용과 간편한 진행 방법 으로 인해 이명을 진단하고 문제점을 확인하기 위해 사용되는 보편적인 검사 방법 중 하나이다. 하지만 현재까지 개발된 이명 
설문지의 경우, 종류가 10 개 이상으로 다양하고 각 설문지는 개발 목적 및 문항 구성 요소의 차이가 있어 이명 설문지를 효 율적으로 사용하기 위해서는 종류에 따른 특징을 정확하게 파 악할 필요성이 있다(Meikle et al., 2012). 본 연구에서는 현재 임상에서 주로 사용되는 이명 설문지인 이명장애설문지(Tinnitus Handicap Questionnaire, THQ), 이명장애지수(Tinnitus Handicap Index, THI), 이명 기능 지수(Tinnitus Functional Index, TFI), 이명주요기능설문지(Tinnitus Primary Functional Questionnaire, TPFQ)의 개발 배경 및 목적, 개발 과정, 설문 지 문항 특징, 신뢰도 검증 결과, 설문지의 장점 및 단점에 관한 선행연구를 정리하여 임상에서 효과적인 이명 설문지의 사용 을 위한 이해를 돕고자 한다.

\section{MATERIALS AND METHODS}

이명설문지는 개발 시기 순서에 따라 THQ, THI, TFI, TPFQ 순으로 기술하였으며, 하위 범주, 문항 수, 설문지 점수의 해석, 설문지의 신뢰도 결과는 Table 1에 요약하여 제시하였다.

\section{Tinnitus Handicap Questionnaire}

이명장애설문지(THQ)가 개발되기 전 1970년대까지는 이명을
경험하거나 이명으로 인한 문제를 호소하는 환자들의 보고는 다수 있었으나 이명의 영향으로 인한 부차적인 문제를 확인하 는 설문지가 개발되지 않았었다. 그 당시 6 17\% 정도의 인구가 이명을 경험하였으며, 난청인의 경우 70 85\% 정도의 사람들이 이명을 동반한다고 보고했다(Chung et al., 1984; Fowler, 1944; Glasgold \& Altmann, 1966; House \& Brackmann, 1981).

당시 많은 연구자는 이명의 정도를 측정하기 위한 검사의 중 요성을 강조하였으며, 이를 위해서는 이명에 영향을 미치는 요 소들을 파악하는 것이 중요하다고 언급하였다(Kuk et al., 1990; Vernon et al., 1980). 예를 들어 Vernon et al.(1980)은 이명 환자 의 $85 \%$ 이상이 청력손실을 동반한다고 보고하였다. Tyler \& Baker(1983)에 의하면 수면(falling asleep), 질환의 지속성(the persistence of the disorder), 언어 이해력(understanding of speech), 절망(despair), 짜증(annoyance), 집중력 저하(difficulty with concentration), 약물 의존성(drug dependence)과 같은 문제들이 이명과 관련되어 있다고 보고했다. 또한, Stephens \& Hallam(1985) 연구에서 이명은 신경 증상을 측정하는 방법인 Crown-Crisp Experiential Index의 불안(anxiety), 강 박관념(obsessionality), 신체적 불안(somatic anxiety), 우울증 (depression), 히스테리(hysteria) 척도 중에서 불안과 우울 척 도에 깊은 연관성을 가지고 있다고 보고했다. Kuk et al.(1990)

Table 1. Comparison of characteristics for four tinnitus questionnaires

\begin{tabular}{|c|c|c|c|c|}
\hline \multirow{2}{*}{ Characteristic } & \multicolumn{4}{|c|}{ Type of questionnaire } \\
\hline & THQ & THI & TFI & TPFQ \\
\hline Subcategory & $\begin{array}{l}\text { Social/emotional/ } \\
\text { physical }\end{array}$ & $\begin{array}{l}\text { Functional/emotional/ } \\
\text { catastrophic }\end{array}$ & $\begin{array}{l}\text { Intrusive/cognitive/ } \\
\text { sense of control/ } \\
\text { sleep/relaxation/ } \\
\text { quality of life/ } \\
\text { auditory/emotional }\end{array}$ & $\begin{array}{l}\text { Emotion/hearing/ } \\
\text { sleep/concentration }\end{array}$ \\
\hline Number of questions & 27 & 25 & 25 & 20 \\
\hline Score interpretation & $\begin{array}{l}0-100: \\
\text { The larger total score of } \\
\text { the THQ represents the } \\
\text { more severe } \\
\text { the handicap }\end{array}$ & $\begin{array}{l}\text { 78-100: catastrophic } \\
\text { 58-76: severe } \\
\text { 38-56: moderate } \\
\text { 18-36: mild } \\
\text { 0-16: slight or } \\
\text { no handicap }\end{array}$ & $\begin{array}{l}73-100: \text { very big problem } \\
54-72 \text { : big problem } \\
\text { 32-53: moderate problem } \\
\text { 18-31: small problem } \\
0-17: \text { not a problem }\end{array}$ & $\begin{array}{l}0-100: \\
\text { The larger total score of } \\
\text { the TPFQ represents the } \\
\text { more severe the handicap }\end{array}$ \\
\hline $\begin{array}{l}\text { Reliability of original } \\
\text { version (inter-item } \\
\text { consistency) }\end{array}$ & $\mathrm{O}(\mathrm{alpha}=0.94)$ & $\mathrm{O}($ alpha $=0.93)$ & $\mathrm{O}(\mathrm{alpha}=0.97)$ & $\mathrm{O}($ alpha $=0.92)$ \\
\hline $\begin{array}{l}\text { Reliability of Korean } \\
\text { version (inter-item } \\
\text { consistency) }\end{array}$ & $\mathrm{O}(\mathrm{alpha}=0.96)$ & $\mathrm{O}(\mathrm{alpha}=0.95)$ & $\mathrm{X}$ & $\mathrm{X}$ \\
\hline Key references & $\begin{array}{l}\text { Kuk et al., } 1990 \\
\text { Jun et al., } 2015\end{array}$ & $\begin{array}{l}\text { Newman et al., } 1996 \\
\text { Newman et al., } 1998 \\
\text { Kim et al., } 2002\end{array}$ & Meikle et al., 2012 & Tyler et al. 2014 \\
\hline
\end{tabular}

'O' represents that the reliability was evaluated and ' $\mathrm{X}$ ' represents that the reliability was not evaluated. THQ: Tinnitus Handicap Questionnaire, THI: Tinnitus Handicap Index, TFI: Tinnitus Functional Index, TPFQ: Tinnitus Primary Functional Questionnaire 
은 위에서 언급한 이명으로 인해 나타나는 부수적인 현상들의 영향을 측정할 수 있는 이명 설문지를 제안하였다. 초기 설문 지는 Tyler \& Baker(1983)의 보고서를 기반으로 87개의 문항 으로 구성하였다. 87 개 문항은 청력(hearing, 12 개 문항), 생활 방식(life-style, 27개 문항), 건강(health, 18 개 문항), 감정 (emotion, 20개 문항), 이명을 겪는 사람에 대한 타인의 생각 (10개 문항)으로 구성되어 있었다. 이후 설문지의 내적일치도 (크론바흐알파계수)를 높이기 위해 문항의 중복성과 민감성이 떨어지는 문항들을 고려하여 상관관계가 낮은 59 개의 문항을 제외하고 최종적으로 27 개의 문항을 선별하였으며, Tinnitus Handicap Questionnaire (THQ)라 명명하였다.

$\mathrm{THQ}$ 는 사회적 문항 $(9,14,16,17,19)$, 정서적 문항(11, 13, $18,22,24,27)$, 신체적 문항 $(1,12,15,20)$ 의 3 개의 척도로 분류 되며 0 100점의 점수 범위를 가진다. 예를 들어, 요인 1(이명의 신체적, 정서적, 사회적 영향)은 '이명 때문에 집중할 수가 없다' 또는 '이명 때문에 밤에 잠들기가 어렵다'와 같은 문항들로 구 성되어 있으며, 요인 2(이명을 겪는 사람의 청각적 능력)는 '이명 때문에 소리가 어디서 나는지 분간하기 어렵다'와 '이명 때문에 소음이 있는 곳을 피한다'와 같은 문항들로 구성되어 있다. 또 한 요인 3(이명에 대한 인식)은 '나의 이명은 매년 나빠진다' 또 는 '다른 사람들은 이명이 얼마나 고통스러운지를 모른다'와 같 은 문항들로 구성되어 있다. 설문 점수를 계산하는 방법은 요 인 1과 요인 2의 경우 요인별 문항에 해당하는 점수를 총합한 이후 백분율로 환산하는 방법이 사용되었다. 요인 3 은 문항 25 , 26의 점수가 낮은 경우 이명의 심각성이 두드러지도록 구성했 기 때문에 100점에서 측정된 점수를 빼고 요인 3의 다른 문항 들과 더한 뒤 백분율로 환산하는 방법을 사용한다. $\mathrm{THQ}$ 의 총 점은 요인 $1,2,3$ 의 점수를 모두 더하여 백분율로 환산하여 최 종 점수를 산출한다.

$\mathrm{THQ}$ 설문지의 점수가 높을수록 이명으로 인한 불편함이 증 가함을 나타낸다. 이명으로 인한 불편함은 두 가지 방법으로 판단할 수 있다. 첫 번째, 방법은 $\mathrm{THQ}$ 의 총합 점수를 확인하 는 것이다. 또 다른 방법은 Kuk et al.(1990)의 표준 데이터와 설문지 대상자 데이터를 비교하는 방법이 있다. 예를 들어 $\mathrm{THQ}$ 설문지의 총점 또는 요인 $1,2,3$ 의 점수를 이명을 경험하 는 사람들의 평균 점수를 나타낸 표준 데이터와 비교하는 것이 다. 임상적으로 $\mathrm{THQ}$ 의 요인 1 또는 요인 2에 해당하는 점수는 이명을 겪는 사람에게 치료를 제공하기 위한 통찰력을 제공한 다. 예를 들어 요인 1과 요인 2의 각 척도 점수가 모두 높은 경 우에는 이명으로 인한 신체적, 정서적, 사회적 어려움이 청력에 의해서 영향을 받고 있을 가능성을 보여준다. 즉, 치료 프로그 램에 이명 관리(예: 상담) 이외에 적절한 증폭 장치 사용을 고 려해야 한다. 한편, 요인 1 의 점수가 높지만 요인 2 의 점수가 낮
은 경우에는 이명에 대한 어려움이 주로 사회적, 정서적 및 신 체적 측면의 영향에서 기인한다고 볼 수 있다. 이는 이명을 겪 는 대상이 청력으로 인한 이명의 어려움이 적거나 청력 저하로 인한 이명의 어려움에 효과적으로 대처할 수 있음을 보여준다. 이 경우 요인 1에서 어려움을 호소한 영역을 고려하여 이명 재 활을 진행하고 만약 청력역치 결과가 높다면 적절한 증폭의 사 용은 효율적일 수 있다고 제시하고 있다(Kuk et al., 1990). 요 인 1과 요인 2의 점수가 모두 낮은 경우는 경도의 이명으로 해 석할 수 있으며 상담을 통한 재활 방법을 권고할 수 있다. 요인 1 의 점수가 낮지만 요인 2의 점수가 높은 경우에는 사회적, 정 서적, 신체적 측면에서 이명에 대한 어려움을 크게 보이지는 않 지만, 증폭을 위한 개입이 필요함을 나타낸다. 요인 3의 경우 점수 결과를 단독으로는 활용하지 않는 것을 권고한다. 그 이 유는 내적일치도의 신뢰도 값이 요인 1과 요인 2에서 높게 보인 반면 요인 3의 경우 낮은 신뢰도를 보였기 때문에 안정성이 떨 어진다고 보고하고 있기 때문이다. 이처럼 $\mathrm{THQ}$ 는 이명으로 인 해 발생하는 사회적, 정서적, 신체적, 청각적 측면의 어려움을 파악하여 이명 재활 계획 수립을 위한 기초를 제공할 수 있다.

$\mathrm{THQ}$ 설문지의 신뢰도 검증 결과 내적일치도는 $\alpha=0.94$ 로 신 뢰도가 높은 것으로 나타났으며, 전체-문항 간의 상관관계는 $\mathrm{r}=$ $0.15 \sim 0.81$ 의 범위였다. 또한, 각 요인 1, 요인 2 , 요인 3 의 각각의 신뢰도 결과는 각각 $\alpha=0.95, \alpha=0.88, \alpha=0.47$ 로 나타났다. 내적일치도는 문항의 신뢰성을 평가하는 척도로 계수는 0 에서 1 사이의 범위로 표기하며, 결과 값이 높을수록 신뢰도가 높다 고 해석한다. 보통 0.5 이상을 신뢰도를 인정할 수 있는 최소기 준으로 판단하며, 0.7 이상은 신뢰도가 높다고 해석하고, 0.8 이 상이면 신뢰도가 매우 높은 것으로 해석한다. 요인 3의 내적일 치도의 신뢰도가 낮은 이유는 문항의 수(4개 문항)가 적고 문 항 간의 상관관계가 낮기 때문이라고 보고하고 있다. $\mathrm{THQ}$ 의 총 점수 간 상관계수를 피어슨 상관계수로 비교한 결과, 이명의 크기 평가(tinnitus loudness judgement)는 $r=0.57$, 삶의 만족 도(life satisfaction)는 $\mathrm{r}=-0.54$, 평균 청력역치(mean hearing threshold)는 $r=0.52$, 우울증(depression)은 $r=0.63$, 일반 건강 상태(general health status)는 $r=0.54$ 의 값을 보였다. 하지만 음 량검사(loudness match)는 $r=0.32$, 최소차폐강도(minimum masking level)는 $r=0.26$ 값으로 낮은 상관계수 값을 보였다. 피어슨 상관계수는 두 변수 간에 선형적 관계를 분석하는 방법 이다. $p$ 값의 절대값에 따라서 상관관계의 정도를 판별할 수 있 다. 예를 들어 $p$ 값의 절대값이 0 에서 0.1 사이의 값을 가지면 거 의 상관관계가 없다고 해석할 수 있고 0.1 에서 0.3 사이의 값을 가지면 약한 상관관계로 해석할 수 있다. 0.3 에서 0.7 사이의 값 을 가지면 뚜렷한 상관관계를 가지며, 0.7 에서 1 사이의 값을 가 지면 강한 상관관계를 가진다고 해석할 수 있다. 다중회귀분석 
결과 요인 1 은 인지된 이명의 크기와 일반적인 건강 상태 측정 에 주로 기여하는 반면 요인 2는 평균 청력손실 점수 예측에 기 여하는 것으로 나타났다 $(p<0.05)$. 요인 1과 요인 3은 삶의 만 족도와 우울증을 예측하는 것으로 나타났다. 하지만 요인 1,2 , 3은 음량검사, 최소차폐강도, 증상 보고(symptom report), 기 능적 상태(functional status), 질병의 수(the number of illnesses), 사회적 열망(social desirability)과는 상관성이 낮은 것 으로 나타났다.

$\mathrm{THQ}$ 는 영어, 프랑스어, 네덜란드어 등을 포함하여 다양한 언 어로 번역되어 신뢰도 분석이 이루어졌다. 예를 들어 영어, 프랑 스어, 네덜란드어 같은 경우 내적일치도 값은 각각 $\alpha=0.94, \alpha=$ $0.90, \alpha=0.93$ 을 보였으며, 한국어 버전의 Korean version of the THQ (THQ-K)도 $\alpha=0.96$ 으로 본래 THQ 버전과 마찬가 지로 높은 내적일치도를 보여주었다. 또한 THQ-K는 스피어만 상관계수(Spearman rank correlation coefficients) 값이 Korean version of the THI (THI-K)와는 0.843으로 상관성이 높았고, 우울증의 척도인 벡우울척도(Beck Depression Inventory, $\mathrm{BDI}$ ) 는 0.336 , 고통에 대한 시각아날로그척도(visual analog scale)는 0.493 , 음량에 대한 시각아날로그척도는 0.753 으로 상관성이 높 은 것으로 나타났다(Jun et al., 2015). 하지만 THQ-K는 음조검 사, 음량검사, 최소차폐강도와의 상관관계 결과 각각 0.004 , $0.156,0.037$ 값으로 이명의 심리음향검사와 유의미한 상관관계 를 보이지 않았다(Jun et al., 2015).

\section{Tinnitus Handicap Index}

이명장애지수(THI) 설문지는 1996년 Newman 등에 의해 개발되었고(Newman et al., 1996), 1998년 후속 연구를 통해 29명의 성인 이명 환자들을 대상으로 THI의 검사-재검사 신뢰 도를 증명하였다(Newman et al., 1998). 당시에 전문가들은 이 명의 정도(pain severity)와 같은 직접적인 부분뿐만 아니라 그 로 인해 영향을 받는 환자의 삶의 질적인 부분에 관심을 가졌 다. 자가 보고 설문지 형식은 청력검사와 같은 객관적인 검사로 는 확인이 어려운 환자의 주관적인 부분들을 확인할 수 있으므 로, 때문에 이명 자가 보고 설문지를 통해 환자의 일상에서 이 명으로 인한 영향들을 수치화하여 평가하고자 하였다(Newman et al., 1996). 앞서 사용되던 이명 설문지들은 신뢰성 및 타 당성의 검증이 대부분 이루어지지 않거나 해석이 모호한 문항들 이 포함될 수가 있었다. 예를 들어, THQ, Tinnitus Effect Questionnaire, Tinnitus Severity Questionnaire 등은 내적일치도 조 사가 이루어지지 않았으며, Tinnitus Reaction Questionnaire의 경우 일관성 및 재검사 신뢰도가 증명되었지만 고통, 분노와 같 은 정신적인 부분에만 초점이 맞추어져 있는 한계가 있었다 (Newman et al., 1995). 또한 Newman et al.(1995) 연구에서 32
명의 이명 환자들을 대상으로 $\mathrm{THQ}$ 의 검사-재검사 신뢰도 연 구를 한 결과 요인 $1,2,3$ 중 요인 3(이명에 대한 인식)의 경우 검사-재검사 신뢰도가 부적합했다. Newman은 이러한 부분을 보완하기 위한 목적으로 THI를 개발하였다. THI는 임상에서 사용하기에 용이하도록 설문지의 문항을 이해하기 쉽게 구성하 였으며, 이명으로 인해 동반되는 일상생활의 문제점을 평가할 수 있는 문항들을 포함하였다.

THI는 총 100 점 만점이며, 문항당 4점 만점으로 25 개의 질 문 항목으로 구성되어 있다. '예'라면 4점, '가끔 혹은 때때로'일 경우 2점, '아니오'는 0점을 기준으로 하며, 각 질문의 점수를 합 하여 총합 점수를 산출할 수 있다. 총합 점수에 따라 이명을 평 가해 볼 수 있는데, 총합이 78 100점인 경우 심도 수준의 장애 (catastrophic handicap), 58 76점인 경우 고도 수준의 장애 (severe handicap), 38 56점인 경우 중도 수준의 장애(moderate handicap), 18 36점인 경우 경도 수준의 장애(mild handicap), 그리고 0 16점인 경우 거의 장애가 없는 경우(slight or no handicap)로 분류할 수 있다. THI의 척도는 3가지로 구성되어 있다(기능하위척도 11 문항, 정서하위척도 9문항, 재앙화하위척 도 5 문항). 예를 들어, 기능하위척도는 '이명 때문에 집중하기가 어렵습니까?', '이명 때문에 밤에 잠을 자기가 어려우십니까?'와 같이 이명으로 인해 나타나는 삶의 기능적인 측면을 확인할 수 있는 문항들로 구성되었으며, 정서하위척도의 경우 '이명으로 인해 화가 날 때가 있습니까?', ‘이명 때문에 우울감을 느끼십니 까?'와 같이 이명으로 인해 나타나는 감정의 상태를 확인하기 위한 문항들로 구성되어 있다. 재앙화하위척도는 '이명이 절망 적인 문제라고 생각하십니까?, '이명에 더 이상 대처할 수 없다 고 생각하십니까?와 같이 이명에 대한 두려움을 파악하기 위 한 문항들로 구성되어 있다.

최초로 개발된 알파 버전의 $\mathrm{THI}$ 는 45 개 문항이었고 84 명의 이명 환자를 대상으로 신뢰도를 검증하였다(Newman et al., 1995). 그 결과 내적일치도는 $\alpha=0.97$ 이었고 전체-항목 간의 상 관관계는 $r=0.25 ~ 0.85$ 의 범위였다. 전체-항목 간의 상관관계 가 0.5 이하인 질문 항목들을 제외한 후 현재 사용 중인 베타 버전의 THI를 완성하였다. 베타 버전의 THI 또한 66 명의 이명 환자들을 대상으로 신뢰도를 검증하였다. 그 결과 내적일치도 는 $\alpha=0.93$ 이었으며, 전체-항목 간의 상관관계는 $r=0.22 \sim 0.77$ 의 범위였다. 베타 버전의 모든 항목(25개)의 전체-항목 간 상 관관계는 항목 2(이명의 크기로 인해 다른 사람이 말하는 것 을 듣기가 어렵습니까?')를 제외하고 모두 $r=0.5$ 이상이었다. 항목 2 의 전체-항목 간 상관관계의 경우에는 $\mathrm{r}=0.22$ 였으나 내 용 타당도(content validity)가 높아 최종 문항에 포함되었다고 보고하고 있다. 하위척도의 내적일치도 계수의 경우 기능하위 척도는 $\alpha=0.86(\mathrm{r}=0.27 \sim 0.76)$, 정서하위척도 $\alpha=0.87(\mathrm{r}=$ 
0.56 0.82), 재앙화하위척도 $\alpha=0.68$ ( $\mathrm{r}=0.42$ 0.48)이었다. 또한, 요인부하량(factor loading, 각 요인 내에서 가장 높은 요 인 적재 계수)은 각 요인 내에서 가장 잘 설명할 수 있는 대표 문항으로 기능하위척도에서는 '이명 때문에 집중하기가 어렵습 니까?', 정서하위척도에서는 '이명 때문에 좌절감을 느끼는 경우 가 있습니까?, 재앙화하위척도에서는 '이명을 자신이 통제할 수 없다고 생각하십니까?로 나타났다. 이외에도 각 하위척도 간의 피어슨 상관계수 $r=0.65 ~ 0.93$ 으로 모두 유의하게 밝혀졌다.

$\mathrm{THI}$ 는 한국어 버전으로 번역되어 이명 환자 111 명을 대상으 로 신뢰도 및 타당도 연구가 이루어졌다(Kim et al., 2002). 신 뢰도 분석의 경우 내적일치도 값은 $\alpha=0.95$ 로 높은 내적일치 도를 보였으며, 하위척도계수의 경우 기능하위척도는 $\alpha=0.90$, 정서하위척도는 $\alpha=0.92$, 재앙화하위척도는 $\alpha=0.79$ 였다. 또 한 상관관계 분석을 통해 $\mathrm{THI}$ 의 검사-재검사 신뢰도를 확인하 였을 때 모두 통계적으로 유의미하였다( $\mathrm{r}=0.75 ~ 0.91, p<0.001)$. 타당도의 경우 $\mathrm{THI}$ 와 $\mathrm{THQ}$ 의 상관성을 확인하였으며, 통계적 으로 유의한 상관성을 보이는 것으로 나타났다 $(\mathrm{r}=0.83, p<$ 0.001). 두 설문지는 유사한 수준으로 이명의 정도를 측정해 주 는 것을 알 수 있다. 이처럼 영어 버전의 THI뿐만 아니라 한국 어 번역판 $\mathrm{THI}$ 도 신뢰성 및 타당도가 검증되었고 실제 국내에 서도 많이 활용되고 있다.

\section{Tinnitus Functional Index}

이명기능지수(TFI) 설문지가 개발되기 전 다양한 이명 설문 지가 제작되어 사용되었다(Meikle et al., 2012). 하지만 이전 설 문지들은 1 2가지의 문제점만을 이명과 연관을 지어 평가하는 제한점이 있었다. 따라서 다양한 요인들이 이명에 미치는 영향 을 확인하기 위해서는 몇 개의 설문조사를 중복적으로 해야 하므로 금전적 부분과 시간적인 불편함에 대한 의견이 나타나 기 시작했다. 앞서 언급한 문제점을 보완할 수 있는 새로운 이 명 설문지의 제작에 대한 필요성이 요구되었고, 2003년 이명 연 구 컨소시엄(Tinnitus Research Consortium, TRC)에서 새로 운 이명 설문지의 개발을 공식적으로 제기했다(Henry et al., 2016). Meikle은 최초 제안서를 작성하여 연구 승인을 받은 뒤 2004년부터 설문지 제작에 착수하게 되었다. TFI 설문지 제작 에는 17 명의 이명 전문가들로 구성되었으며, 이들 중 8 명은 이 전 이명 설문지 개발에 참여했던 경험이 있었다. TFI가 개발되 기 이전에 TRQ, THQ, THI를 포함하여 10 개 내외의 이명 설 문지가 개발되어 사용되고 있었지만, 이명으로 인해 나타나는 부수적인 현상(예: 수면 문제 등)을 종합적으로 평가할 수 있는 설문지가 부재하여 종합적인 이명 평가를 위해서는 여러 설문 지 검사를 중복적으로 시행하여야만 하였고, 이로 인해 많은 시간적 소모와 높은 검사 비용이 요구되는 등의 부정적인 의견
이 이명 연구 컨소시엄(TRC, 2003)을 통해 보고되었다. 따라서 Meikle et al.(2012)은 이명의 정도와 이명으로 인해 나타나는 부수적인 현상을 종합적으로 평가할 수 있는 설문지 개발에 초 점을 두어 개발하였고, 그 설문지를 Tinnitus Functional Index (TFI)라 명명하였다(Meikle et al., 2012).

$\mathrm{TFI}$ 는 다음의 7 가지 중점 사항들을 고려하여 개발되었다 (Meikle et al., 2012). 첫째, 기존에 개발된 9개의 이명 설문지에 서 사용된 175 개 문항의 타당성(validity)을 비교하여, 이 중 대 상자의 재활 효과를 높은 민감도로 나타내는 질문들로 선별해 구성했다. 둘째, TFI는 이명과 관련성이 높은 하위 범주를 8 개 로 나누어 문항들을 구성하였다. 8 개의 하위 범주는 통찰력 (intrusive), 감지(sense of control), 인지(cognitive), 수면 (sleep), 청각(auditory), 완화(relaxation), 삶의 질(quality of life), 그리고 감정(emotional) 영역이다. 셋째, TFI는 설문 시간 의 최소화를 고려하여 25 개의 문항만을 선별하여 구성하였다. 넷째, 효과적인 응답률을 위해 미국인들이 가장 선호하는 10 점 (0 10점) 척도를 사용하였다. 다섯째, 이해도를 높이기 위하여 쉬운 단어로 구성하여 대상자들의 이해도를 높이려 하였다. 여 섯째, 설문지의 내용 중 이명 대상자에게 부정적 영향을 미치 는 문항들은 배제했다. 일곱째, 결과의 평가 시 채점과 해석이 용이할 수 있도록 구성하였다.

$\mathrm{TFI}$ 는 최종적으로 삶의 질 범주(4개 문항)를 제외한 각각의 범주별 3 개의 문항으로 이루어져 전체 25 개의 문항으로 제작되 었으며, 점수를 계산하는 방법은 다음과 같다. 문항별 응답한 점수 결과를 모두 더해준 값에 응답한 문항 개수만큼 나눠준 뒤 결과 값에 10 을 곱하면 된다. 예를 들어 20 개의 문항에 답한 결과를 모두 더한 다음 문항의 수만큼 나눠 10 을 곱하면 값이 나온다. TFI 설문지는 5 가지 하위척도로 나누어져 있으며, 0 17점은 문제 없음(not a problem), 18 31점은 작은 문제(small problem), 32 53점은 보통 문제(moderate problem), 54 72점 은 큰 문제(big problem), 73 100점은 매우 큰 문제(very big problem)로 분류된다. 결과 값이 25 보다 작은 경우 비교적 가 벼운 이명으로 분류하며, 25 50점 사이에 해당될 때 이명에 대 한 중재와 전문가의 개입이 요구되며, 50점보다 큰 경우 적극적 인 중재가 필요한 심각한 이명으로 나누어 평가할 수 있다. 또 한, 설문 응답 시 최소 19 개의 질문 항목(문항의 $76 \%$ )에 답변해 야만 설문의 결과에 유효성을 얻을 수 있다. 질문의 유형과 답 하는 방식을 예를 들자면 '지난주 동안 일상생활 중 이명으로 인해 불편함을 느끼는 시간이 얼마나 되었는가?'와 같은 유형 으로 질문이 이루어져 있고, 답변은 0 10점 척도 중 해당하는 점수를 표시하면 된다.

Meikle et al.(2012)은 TFI 설문지의 신뢰도 및 타당성 평가를 $\mathrm{THI}$ 설문지와 점수 비교를 통해 검증하였다. 평가 방식은 인터 
넷 사이트를 통해 이명을 겪고 있는 167 명의 참가자를 모집하여 이들 중 77 명의 훈련군 그룹과 90 명의 대조군 그룹으로 구분하 여 전화이명교육(telephone tinnitus education) 방식으로 진행 성 이명 관리(Progressive Tinnitus Management)를 6개월간 시 행한 뒤 재활 전후의 설문지 검사 결과를 비교하여 설문 내용의 민감도를 확인하였다. 결과 통계는 Cohen's d 통계법을 사용하 여 척도를 비교하였다. Cohen's d는 집단 간 차이의 표준화 측 정치로서 집단 평균값의 차이를 표준편차로 나누어 효과 크기 를 비교하는 검증방법이다. Cohen's d는 집단 간 차이의 표준치 와 효과 크기(effect size)를 비교하는 통계 기법이며, 결과 값이 클수록 검증력이 더 높다고 해석할 수 있다(Cohen, 1988). TFI 와 THI 두 설문지 간의 훈련 전후에 따른 재활 효과를 비교한 결과는 THI는 Cohen's $\mathrm{d}=1.04$ 였으나 TFI의 경우에는 $\mathrm{d}=$ 1.23 으로 더 높은 결과를 얻을 수 있었다. 이러한 결과를 토대 로 TFI 설문지는 THI 설문지보다 재활 훈련 전후에 따른 재활 효과에 대한 민감도가 높다고 보고하였다(Meikle et al., 2012). 두 설문지 결과의 표준편차 결과는 THI가 18.67, TFI는 18.19로 두 설문지 모두 이명의 변화에 민감한 것으로 나타났다. TFI가 개발된 2012년 이후 2014년까지 영국(Fackrell et al., 2015), 뉴질 랜드(Chandra et al., 2018), 미국(Henry et al., 2015; Scherer et al., 2014), 네덜란드(Rabau et al., 2014) 등을 포함한 14개의 언어 로 번역이 진행되어 사용되고 있으며, 현재까지 TFI 한국어 버 전의 신뢰도 검증은 진행되지 않은 상태이다.

\section{Tinnitus Primary Function Questionnaire}

이명주요기능설문지(TPFQ)가 개발되기 전 기존 이명 설문 지들은 이명으로 인한 삶의 질과 이명의 정도를 평가하기 위한 목적으로 개발되어 사용되었으며(Tyler et al., 2014), 대부분의 이명 설문지는 이명으로 인한 이차적인 영향(예: 삶의 질 등)들 을 하위 범주로 구성하여 이명의 영향을 종합적으로 평가하였 다. 예를 들어, THQ는 요인 1(이명의 신체적, 정서적, 사회적 영 향), 요인 2(이명을 겪는 사람의 청각적 능력), 요인 3(이명에 대 한 인식)의 하위 범주로 구성하여 이명으로 인한 삶의 질, 청각 적 능력, 그리고 이명으로 인한 어려움을 평가하였으며(Kuk et al., 1990), THI는 기능, 정서, 재앙화 척도로 구성하여 이명으로 인한 기능적, 정서적, 재앙화에 대한 영향을 평가하도록 문항들 을 구성하였다(Newman et al., 1998). 하지만 Tyler et al.(2014) 연구에서는 이명으로 인해 발생하는 주요한 이차적 영향은 감정 (emotion), 청각(hearing), 수면(sleep), 집중력(concentration)이 며 이러한 각 하위 항목들이 이명에 미치는 영향과 각 하위 항 목의 영향을 종합한 이명의 영향을 모두 측정하는 설문지의 개 발이 필요함을 제안하였다. 따라서 $\mathrm{TPFQ}$ 설문지는 이명을 경 험하는 사람들이 삶에 미치는 영향에 대해 초점을 맞춰 감정,
청각, 수면, 집중력으로 하위 항목을 구성하였으며, 종합적인 평 가뿐만 아니라 각 하위 항목에 대한 독립적인 평가가 가능하도 록 구성하는 데 초점을 두었다. 또한 상담 및 재활에 효과적인 정보를 제공하고 재활 전후 이명의 변화를 민감하게 측정할 수 있는 도구로 개발하고자 하였으며, 설문지를 Tinnitus Primary Function Questionnaire (TPFQ)라 명명하였다(Tyler et al., 2014). $\mathrm{TPFQ}$ 설문지는 개인적인 영향을 포함하는 삶의 질과 사회 화(socialization), 신체 건강(physical health), 업무(work), 교 육(education), 경제(economic)와 같은 일상생활의 제한 사항들 을 배제하고, 이명으로 인해 발생하는 주요한 4가지 기능 손상 (감정, 청각, 수면, 집중력)의 정도를 측정하기 위해 개발되었다 (Tyler et al., 2014). 하위 범주별 5개의 문항을 포함하여 총 20 개의 문항으로 구성하였고, 각 하위 범주별 타당성(validity)을 확인하기 위해 158 명 대상자에게 THQ, BDI, 특성 불안 설문지 (Trait Anxiety Questionnaire), 피츠버그 수면 질 지수(Pittsburgh Sleep Quality Index, PSQI) 설문지와의 비교를 통해 항목 간 피어슨 상관계수를 확인하였다. 또한 확인적 요인 분석 (confirmatory factor analysis)을 통해 높은 부하량(loadings) 을 나타낸 문항을 3 개씩 선별하여 총 12 문항의 설문지를 추가 적으로 구성하여 TPFQ 설문지는 20문항과 12 문항 2 가지 버전 으로 개발되었다(Tyler et al., 2014).

20 문항과 12문항으로 구성된 2가지 TPFQ는 문항별 100점 만점으로 전체 문항 점수의 평균 점수로 환산하여 이명에 대한 기능 손상 정도를 측정할 수 있다. 예를 들어, 감정 범주는 '나 는 이명 때문에 괴롭다, '나는 이명 때문에 우울하다'와 같이 이 명으로 인한 감정적인 영향을 확인하며, 청각 범주는 '이명 때 문에 잘 들리지 않는 말소리가 있다, '이명이 나에게 미치는 최 악의 영향 중 하나는 청력손실(난청)보다 이명으로 인해 말소리 를 듣기 더 어렵다는 점이다와 같이 청력이 이명으로부터 미치 는 영향을 확인하는 문항으로 구성되었다. 또한, 수면 범주는 '이명 때문에 밤새 잠을 이루지 못한다', '밤중에 잠에서 깼을 때, 이명 때문에 다시 잠을 이루기가 힘들다'와 같이 이명이 수 면에 미치는 영향을 확인하며, 집중력 범주는 '이명 때문에 내 업무에 집중하는 것이 어렵다고 느낀다', '이명으로 인해 중요한 일들에 주의를 집중하기 어렵다와 같이 이명으로 인한 집중력 에 대한 영향을 확인하는 문항들로 구성되어 있다. 각각의 범 주별 하위 점수를 허용하여, 각 범주별 평균 점수를 통해 점수 결과에 따라 상담 및 재활에 대한 지표로 사용할 수 있다.

$\mathrm{TPFQ}$ 설문지는 4가지 설문지(THQ, BDI, Trait Anxiety Questionnaire, PSQI) 검사 결과와 비교를 통해 신뢰도 및 타 당도를 검증하였다. 20 문항 버전 $\mathrm{TPFQ}$ 의 신뢰도 검증 결과, 내 적일치도와 전체-항목 간의 상관관계를 통해 신뢰도를 확인하 였을 때, 20 개의 항목 모두 내적일치도가 $\alpha=0.92$ 값을 보였으 
며 4가지 하위 범주의 집중력 범주에서 $\alpha=0.88$, 청력 범주에 서 $\alpha=0.81$, 감정 범주에서 $\alpha=0.84$, 수면 범주에서 $\alpha=0.94$ 로 높은 상관성을 나타내고 전체-항목 간의 상관관계는 $\mathrm{r}=$ 0.36 0.80의 범위로 나타났다. 타당도 검증 결과, TPFQ와 $\mathrm{THQ}, \mathrm{BDI}$, Trait Anxiety Questionnaire, PSQI 간의 상관관계 (피어슨 상관계수) 값은 $r=0.52 ~ 0.77$ 로 모두 유의미하게 나타났 으며, 감정 범주와 THQ, BDI, Trait Anxiety Questionnaire 간 의 상관계수 및 수면 범주와 PSQI 간의 상관계수, 집중력 범주 와 $\mathrm{THQ}$ 설문지 간의 상관계수 모두 $\mathrm{r}=0.65 \sim 0.69$ 로 모두 유의 미하게 나타났다. 12 문항 버전의 $\mathrm{TPFQ}$ 도 20 문항 버전의 $\mathrm{TPFQ}$ 와 동일한 방법으로 신뢰도 및 타당도를 검증하였다. 12 문항 $\mathrm{TPFQ}$ 의 내적일치도 검사 결과, $\alpha=0.89$ 값을 나타냈으며, 집중력 범주에서 $\alpha=0.89$, 감정 범주에서 $\alpha=0.90$, 청력 범주에 서 $\alpha=0.90$, 수면 범주에서 $\alpha=0.93$ 으로 나타났다. 타당도 검사 결과는 12 문항의 TPFQ와 THQ, BDI, Trait Anxiety Questionnaire, PSQI 간의 피어슨 상관계수 $r=0.49 \sim 0.77$ 로 모두 유의미 하게 나타났다. 또한 Tyler et al.(2014)은 TPFQ의 재활 전후의 점수 결과에 대한 신뢰도 검증을 위해 $\mathrm{THQ}$ 와 비교를 통해 신 뢰도 검증을 하였으며, 이명을 경험하는 대상자 100명으로부터 12 개월간의 재활 전후 점수 결과를 대응표본 $t$ 검정(paired sample $t$-test)을 통해 비교하였다. 20 문항 버전의 TPFQ와 $\mathrm{THQ}$ 의 검사 결과, $\mathrm{TPFQ}[t(99)=3.85, p<0.001]$ 와 $\mathrm{THQ}$ $[t(99)=5.08, p<0.001]$ 모두 유의미한 개선을 보였으며, 12 문 항 $\mathrm{TPFQ}$ 와 $\mathrm{THQ}$ 를 비교한 결과 또한 $\mathrm{TPFQ}[t(99)=6.56, p<$ 0.001], THQ [ $t(99)=5.08, p<0.001] 20$ 문항과 12문항 버전의 $\mathrm{TPFQ}$ 설문지 모두 재활 효과에 대해 민감도가 높게 나타났다. $\mathrm{TPFQ}$ 는 현재 $\mathrm{TPFQ}$ 의 한국어 버전의 개발 및 신뢰도 검증은 아직 이루어지지 않고 있다.

\section{CONCLUSIONS}

이명과 관련된 연구 중 이명의 기전은 달팽이관, 중추신경계, 말초신경계 등으로 발생 기전의 위치를 좁혀 가고 있다(Bauer, 2004). 하지만 이명의 발병 원인과 그 증상을 객관화하기에는 여전히 한계가 있으므로 이명 재활에 따른 재활 효과의 객관적 인 측정에도 어려움이 있다. 이러한 이유로 이명의 정도를 측정 하는 주관적 검사 도구인 이명 설문지의 목적과 특성을 정확하 게 파악하여 사용하는 것은 이명 정도의 측정과 이명 재활의 효과를 확인할 수 있는 가장 보편적인 방법이라고 할 수 있다

(Meikle et al., 2012).

본 연구는 이명의 주관적 증상을 확인하기 위해 현재 개발되 어 사용되고 있는 다양한 이명 설문지 중 보편적으로 사용되고 있는 4가지 이명 설문지(THQ, THI, TFI, TPFQ)의 특징을 개
발 배경 및 목적, 설문지 특성 및 해석 방법, 신뢰도 측정 결과 로 분류하여 제시하였다. 각 설문지의 특성과 목적을 정확하게 확인하여 적용한다면 효과적인 이명 정도의 측정과 재활에 따 른 이명의 완화 정도를 효율적으로 측정할 수 있을 것이다.

중심 단어 : 이명장애설문지·이명장애지수·이명기능지수· 이명주요기능설문지.

\section{Acknowledgments}

이 성과는 2018년도 정부(과학기술정보통신부)의 재원으로 한국 연구재단의 지원을 받아 수행된 연구임(NRF-2018R1C1B6003765).

\section{REFERENCES}

Bauer, C. A. (2004). Mechanisms of tinnitus generation. Current Opinion in Otolaryngology and Head and Neck Surgery, 12(5), 413-417.

Chandra, N., Chang, K., Lee, A., Shekhawat, G. S., \& Searchfield, G. D. (2018, July 20). Psychometric validity, reliability, and responsiveness of the tinnitus functional index. Journal of the American Academy of Audiology. [Epub ahead of print]. https://doi.org/10.3766/jaaa.16171.

Chung, D. Y., Gannon, R. P., \& Mason, K. (1984). Original papers.travaux originaux: Factors affecting the prevalence of tinnitus. Audiology, 23(5), 441-452.

Cohen, J. (1988). Statistical Power Analysis for the Behavioral Sciences (2nd ed). (pp. 19-66). Hillsdale, NJ: Lawrence Erlbaum Associates.

Fackrell, K., Hall, D. A., Barry, J. G., \& Hoare, D. J. (2015). UK validation of the Tinnitus Functional Index (TFI) in a large research population. Trials, 16(Suppl 1), 20.

Fowler, E. P. (1944). Head noises in normal and in disordered ears: Significance, measurement, differentiation and treatment. Archives of Otolaryngology-Head and Neck Surgery, 39(6), 498-503.

Glasgold, A. \& Altmann, F. (1966). The effect of stapes surgery on tinnitus in otosclerosis. The Laryngoscope, 76(9), 1524-1532.

Henry, J. A., Frederick, M., Sell, S., Griest, S., \& Abrams, H. (2015). Validation of a novel combination hearing aid and tinnitus therapy device. Ear and hearing, 36(1), 42-52.

Henry, J. A., Griest, S., Thielman, E., McMillan, G., Kaelin, C., \& Carlson, K. F. (2016). Tinnitus functional index: Development, validation, outcomes research, and clinical application. Hearing Research, 334, 5864.

House, J. W. \& Brackmann, D. E. (1981). Tinnitus: Surgical treatment. Ciba Foundation Symposium, 85, 204-216.

Jun, H. J., Yoo, I. W., Hwang, S. J., \& Hwang, S. Y. (2015). Validation of a Korean version of the tinnitus handicap questionnaire. Clinical and Experimental Otorhinolaryngology, 8(3), 198-201.

Kim, J. H., Lee, S. Y., Kim, C. H., Lim, S. L., Shin, J. N., Chung, W. H., et al. (2002). Reliability and validity of a Korean adaptation of the tinnitus handicap inventory. Korean Journal of Otorhinolaryngology-Head and Neck Surgery, 45(4), 328-334.

Kreuzer, P. M., Vielsmeier, V., \& Langguth, B. (2013). Chronic tinnitus: An interdisciplinary challenge. Deutsches Ärzteblatt International, 110(16), 278-284.

Kuk, F. K., Tyler, R. S., Russell, D., \& Jordan, H. (1990). The psychometric properties of a tinnitus handicap questionnaire. Ear and Hearing, 11(6), 434-445.

Meikle, M. B., Henry, J. A., Griest, S. E., Stewart, B. J., Abrams, H. B., McArdle, R., et al. (2012). The tinnitus functional index: Development of a new clinical measure for chronic, intrusive tinnitus. Ear and Hearing, 33(2), 153-176.

Møller, A. R. (2011). Introduction. In Møller, A. R., Langguth, B., DeRidder, D., \& Kleinjung T. (1st ed.). Textbook of Tinnitus (pp. 3-7). New York, NY: Springer. 
Newman, C. W., Jacobson, G. P., \& Spitzer, J. B. (1996). Development of the tinnitus handicap inventory. Archives of Otolaryngology-Head and Neck Surgery, 122(2), 143-148

Newman, C. W., Sandridge, S. A., \& Jacobson, G. P. (1998). Psychometric adequacy of the Tinnitus Handicap Inventory (THI) for evaluating treatment outcome. Journal of the American Academy of Audiology, 9(2), 153-160

Newman, C. W., Wharton, J. A., \& Jacobson, G. P. (1995). Retest stability of the tinnitus handicap questionnaire. Annals of Otology, Rhinology and Laryngology, 104(9 Pt 1), 718-723.

Nondahl, D. M., Cruickshanks, K. J., Wiley, T. L., Klein, R., Klein, B. E., \& Tweed, T. S. (2002). Prevalence and 5-year incidence of tinnitus among older adults: The epidemiology of hearing loss study. Journal of the American Academy of Audiology, 13(6), 323-331.

Rabau, S., Wouters, K., \& Van de Heyning, P. (2014). Validation and translation of the Dutch tinnitus functional index. Acta Oto-Rhino-Laryngologica Belgica, 10(4), 251-258.
Scherer, R. W., Formby, C., Gold, S., Erdman, S., Rodhe, C., Carlson, M., et al. (2014). The Tinnitus Retraining Therapy Trial (TRTT): Study protocol for a randomized controlled trial. Trials, 15, 396.

Scott, B., Lindberg, P., Melin, L., \& Lyttkens, L. (1990). Predictors of tinnitus discomfort, adaptation, and subjective loudness. British Journal of Audiology, 24(1), 51-62.

Stephens, S. D. \& Hallam, R. S. (1985). The crown-crisp experiential index in patients complaining of tinnitus. British Journal of Audiology, 19(2), 151-158.

Tyler, R. S. \& Baker, L. J. (1983). Difficulties experienced by tinnitus sufferers. The Journal of Speech and Hearing Disorders, 48(2), 150-154.

Tyler, R., Ji, H., Perreau, A., Witt, S., Noble, W., \& Coelho, C. (2014). Development and validation of the tinnitus primary function questionnaire. American Journal of Audiology, 23(3), 260-272.

Vernon, J., Johnson, R., Schleuning, A., \& Mitchell, C. (1980). Masking and tinnitus. Audiology and Hearing Education, 6, 5-9. 